\title{
Myroides phaeus sp. nov., isolated from human saliva, and emended descriptions of the genus Myroides and the species Myroides profundi Zhang et al. 2009 and Myroides marinus Cho et al. 2011
}

Correspondence

Xiao-Hua Zhang

xhzhang@ouc.edu.cn

\author{
Shulin Yan, ${ }^{1}$ Naixin Zhao $^{2}$ and Xiao-Hua Zhang ${ }^{1}$ \\ ${ }^{1}$ College of Marine Life Sciences, Ocean University of China, Qingdao, PR China \\ ${ }^{2}$ Weifang Medical University, Weifang, Shandong Province, PR China
}

\begin{abstract}
A novel bacterial strain, designated $\mathrm{MY} 15^{\top}$, was isolated from a saliva sample taken from a student during a teaching experiment in China. Phylogenetic analyses based on 16S rRNA gene sequences showed that the novel strain was most closely related to Myroides marinus $\mathrm{JS}-08^{\top}$, Myroides odoratimimus LMG $4029^{\top}$ and Myroides profundi D25 ${ }^{\top}$ with $96.5 \%, 96.3 \%$ and $96.1 \%$ gene sequence similarities, respectively, demonstrating that the novel strain belonged to the genus Myroides. Strain MY15 ${ }^{\top}$ formed pale yellow colonies that turned to brown on Luria-Bertani (LB) agar and that gave off a characteristic fruity odour. Cells were Gramstaining-negative, rod-shaped and non-motile. The new isolate contained menaquinone 6 (MK-6) as the major respiratory quinone and $\mathrm{C}_{15: 0}$ iso $(51.2 \%), \mathrm{C}_{17: 0}$ iso $3-\mathrm{OH}(12.9 \%)$ and $\mathrm{C}_{13: 0}$ iso $(10.5 \%)$ as the dominant fatty acids. The $\mathrm{G}+\mathrm{C}$ content of the DNA was $34.3 \mathrm{~mol} \%$. On the basis of this study, based on a polyphasic taxonomic approach, strain MY15 ${ }^{\top}$ (=DSM $23313^{\top}=$ LMG $25566^{\top}$ ) represents a novel species of the genus Myroides, for which the name Myroides phaeus sp. nov. is proposed. Emended descriptions of the genus Myroides and of the species M. profundi and M. marinus are also given.
\end{abstract}

The genus Myroides (family Flavobacteriaceae, phylum Bacteroidetes; Hugo et al., 2006) was established by Vancanneyt et al. (1996). It was created when strains originally classified as Flavobacterium odoratum, derived from clinical sources (Holmes et al., 1977), were reclassified as representing two novel species, $M$. odoratus (type species) and $M$. odoratimimus. Three further species of the genus Myroides, M. pelagicus (Yoon et al., 2006), M. profundi (Zhang et al., 2008) and M. marinus (Cho et al., 2011), have since been described and were isolated from seawater and deep-sea sediment. Although the two original species of the genus were repeatedly isolated from clinical sources (Davis et al., 1979; Macfarlane et al., 1985; Ferrer et al., 1995; Hsueh et al., 1995; Green et al., 2001; Yağc1 et al., 2000), recent studies have indicated that they are also common inhabitants of soil and water and behave as low-grade opportunistic pathogens (Hugo et al., 2006). A novel bacterial strain, designated MY15 ${ }^{\mathrm{T}}$, was isolated from a saliva sample obtained from an asymptomatic student during a teaching experiment at Weifang Medical University, China. A further attempt to isolate the bacterium from the same student a

The GenBank/EMBL/DDBJ accession number for $16 \mathrm{~S}$ rRNA gene sequence of Myroides phaeus sp. nov. MY15 ${ }^{\top}$ is GU253339.

A supplementary figure is available with the online version of this paper. week later failed. The aim of the present study was to determine the exact taxonomic position of strain $M Y 15^{\mathrm{T}}$ by using a polyphasic taxonomic approach.

The saliva sample was diluted with sterile saline $(0.9 \% \mathrm{NaCl}$; $\mathrm{w} / \mathrm{v}$ ) and spread onto trypticase soy agar (TSA; Difco) plates that were incubated at $37{ }^{\circ} \mathrm{C}$ for $48 \mathrm{~h}$. Strain MY15 ${ }^{\mathrm{T}}$, which produced a yellow to brown diffusible pigment, was purified by streaking three times on TSA. Cultures were maintained on Luria-Bertani (LB) agar [1.0\% (w/v) tryptone, $0.5 \%(\mathrm{w} / \mathrm{v})$ yeast extract, $1.0 \%(\mathrm{w} / \mathrm{v}) \mathrm{NaCl}, 2.0 \%(\mathrm{w} / \mathrm{v})$ agar] at $28{ }^{\circ} \mathrm{C}$ and preserved at $-80{ }^{\circ} \mathrm{C}$ in sterile saline supplemented with $15 \%$ $(\mathrm{v} / \mathrm{v})$ glycerol.

For 16S rRNA gene sequencing, cells grown in LB broth at $28{ }^{\circ} \mathrm{C}$ for $24 \mathrm{~h}$ were harvested by centrifugation. Extraction and purification of total genomic DNA from the cells and PCR amplification of the $16 \mathrm{~S}$ rRNA gene were performed as described by Jin et al. (2010). The nearly complete $16 \mathrm{~S}$ rRNA gene sequence $(1356 \mathrm{nt})$ of strain $\mathrm{MY} 15^{\mathrm{T}}$ was submitted to GenBank and EMBL to search for similar sequences using the BLAST algorithm. The identification of phylogenetic neighbours and the calculation of pairwise 16S rRNA gene sequence similarities were achieved using the EzTaxon server (http://www.eztaxon.org/; Chun et al., 2007). Multiple sequence alignment was performed by using CLUSTAL_X 1.8 
(Thompson et al., 1997). The phylogenetic trees were constructed using the neighbour-joining, maximum-likelihood and maximum-parsimony methods with Kimura 2state parameter model analyses implemented with the MEGA version 5 program (Tamura et al., 2007). In each case, bootstrap values were calculated based on 1000 replicates. Sphingobacterium spiritivorum DSM 2582 (GenBank no. AJ459411) was used as an outgroup. The 16S rRNA gene sequence of strain MY15 $5^{\mathrm{T}}$ showed the highest similarities to M. marinus JS-08 ${ }^{\mathrm{T}}(96.5 \%)$, M. odoratimimus LMG $4029^{\mathrm{T}}$ (96.3\%), M. profundi D25 ${ }^{\mathrm{T}}$ (96.1\%), M. pelagicus KCTC $12661^{\mathrm{T}}(96.1 \%)$ and M. odoratus ATCC $4651^{\mathrm{T}}(95.5 \%)$. Sequence similarity was $<92 \%$ with other members of the family Flavobacteriaceae. The neighbour-joining tree, showing the phylogenetic relationships between strain MY $15^{\mathrm{T}}$ and closely related species, is presented in Fig. 1. The topology of the maximum-parsimony and maximumlikelihood trees was essentially the same (data not shown). Strain MY $15^{\mathrm{T}}$ clustered within the genus Myroides with 99$100 \%$ bootstrap values in the three phylogenetic trees.

Colony morphology was determined after incubation for $24 \mathrm{~h}$ at $28{ }^{\circ} \mathrm{C}$ on LB agar. Cell morphology was examined using light microscopy (CX; Olympus) and transmission electron microscopy (JEM-1200EX; JEOL) after negative staining with $1 \%(\mathrm{w} / \mathrm{v})$ phosphotungstic acid. Flagellar motility was assessed using the hanging-drop method ( $\mathrm{Hu} \& \mathrm{Li}, 2007$ ). The presence of gliding motility and the production of flexirubin-type pigments were investigated using the methods recommended by Bernardet et al. (2002). Growth under anaerobic conditions was tested on LB agar and TSA that was either supplemented with $0.25 \%$ (w/v) $\mathrm{NaNO}_{3}$ or not supplemented and prepared under a nitrogen atmosphere and incubated in an anaerobic jar (HP015, HiTech) filled with nitrogen. The temperature range for growth was determined on LB agar by incubating cultures at $6,10,18,28,37,42$, and $45{ }^{\circ} \mathrm{C}$ for 5 days and at 0 and $4{ }^{\circ} \mathrm{C}$ for 30 days. The $\mathrm{pH}$ range for growth was tested in LB broth adjusted to $\mathrm{pH}$ 3.5-12 (at intervals of $0.5 \mathrm{pH}$ unit) with citrate/phosphate, Tris/ $\mathrm{HCl}$ or $\mathrm{Na}_{2} \mathrm{CO}_{3} / \mathrm{NaOH}$ buffers (Breznak \& Costilow, 1994). Tolerance to $\mathrm{NaCl}$ was tested in LB broth supplemented with $0-15 \% \mathrm{NaCl}(\mathrm{w} / \mathrm{v}$, at $1 \%$ intervals) at $28{ }^{\circ} \mathrm{C}$. The optimal $\mathrm{pH}$ and the $\mathrm{NaCl}$ concentration for growth were determined spectrophotometrically $\left(\mathrm{OD}_{600}\right)$ with three replicates. Haemolysis was tested by growing cells on blood-agar plates (LB agar supplemented with $6.5 \%$ defibrinated sheep blood) according to the method described by Tindall et al. (2007). DNA hydrolysis was examined using DNase test agar (Oxoid). Activities of constitutive enzymes and biochemical properties were assessed by using the API 20E, API 20NE and API ZYM strips (bioMérieux) and Gram-negative (GN2) MicroPlates (Biolog) according to the manufacturers' instructions. Standard protocols (Beveridge et al., 2007; Tindall et al., 2007) were used to perform Gram,

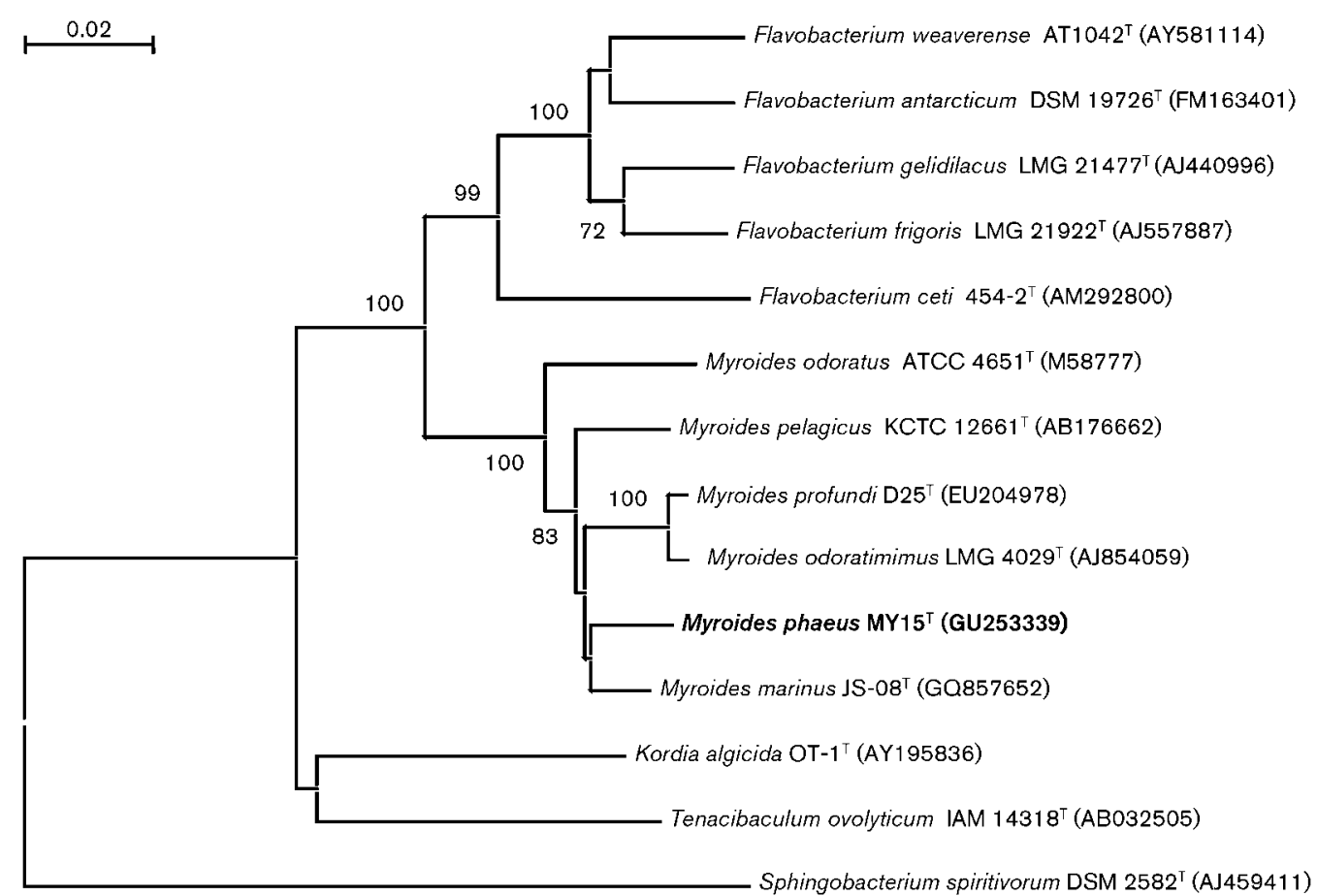

Fig. 1. Neighbour-joining phylogenetic tree based on 16S rRNA gene sequences showing the phylogenetic positions of strain $M Y 15^{\top}$, other species of the genus Myroides and representatives of some other related members of the family Flavobacteriaceae. Sphingobacterium spiritivorum DSM 2582 (GenBank no. AJ459411) was used as an outgroup. Bootstrap values $>70 \%$ (1000 replicates) are indicated at nodes. Bar, 0.02 substitutions per nucleotide position. 
endospore and flagellum staining, to test catalase and oxidase activities and examine nitrite reduction and the degradation of casein, gelatin, Tween 80 , starch, agar, CM-cellulose and egg yolk. The following methods (Tindall et al., 2007) were used in parallel to assess the reliability of the corresponding tests in the API system: nitrate reduction from $\mathrm{KNO}_{3}, \mathrm{H}_{2} \mathrm{~S}$ production from thiosulphate and indole production from L-tryptophan. For the tests mentioned above, $M$. marinus JS$08^{\mathrm{T}}$, M. odoratimimus LMG $4029^{\mathrm{T}}$ and M. profundi $\mathrm{D} 25^{\mathrm{T}}$ were used as reference strains and grown under the same conditions as strain $\mathrm{MY}^{\mathrm{T}}{ }^{\mathrm{T}}$. The morphological, physiological and biochemical characteristics of strain $\mathrm{MY}^{\mathrm{T}} 5^{\mathrm{T}}$ are given in the species description and in Table 1 , and the cellular morphology of strain $\mathrm{MY} 15^{\mathrm{T}}$ is shown in Fig. S1 (available in IJSEM Online). Strain MY $15^{\mathrm{T}}$ mainly differed from recognized species of the genus Myroides by the limited number of carbon sources it was able to oxidize in the GN2 MicroPlate.

Table 1. Differential characteristics of Myroides phaeus sp. nov. compared with other Myroides species

Strains: 1, Myroides phaeus sp. nov. MY15 ${ }^{\mathrm{T}}$; 2, M. marinus JS- $08^{\mathrm{T}}$; 3, M. odoratimimus LMG 4029 $9^{\mathrm{T}}$; , M. profundi D25 ${ }^{\mathrm{T}}$; 5, M. odoratus ATCC $4651^{\mathrm{T}}$ (Vancanneyt et al., 1996; Yoon et al., 2006); 6, M. pelagicus KCTC $12661^{\mathrm{T}}$ (Yoon et al., 2006). Data for strains $1-4$ are from this study, except when otherwise stated. + , Positive; - , negative; $\mathrm{w}$, weakly positive; ND, no data available.

\begin{tabular}{|c|c|c|c|c|c|c|}
\hline Characteristic & 1 & 2 & 3 & 4 & 5 & 6 \\
\hline Colony pigmentation & Yellow to brown & Yellow to orange & Pale yellow & White to pale yellow & Yellow & $\begin{array}{c}\text { Yellow to } \\
\text { orange }\end{array}$ \\
\hline Diffusible pigment on LB agar & $+($ Brown $)$ & $+($ Brown $)$ & + (Pale yellow) & $+($ Pale yellow $)$ & ND & $\mathrm{ND}$ \\
\hline Flexirubin-type pigments & - & + & + & - & $+^{*}$ & $\mathrm{ND}$ \\
\hline Cell size $(\mu \mathrm{m})$ & $0.4-0.5 \times 0.7-1.2$ & $0.2-0.3 \times 0.6-1 \dagger$ & $0.2-0.3 \times 3.5-4 \dagger$ & $0.7-0.9 \times 1.6-2.4 \dagger$ & $0.2-0.3 \times 11-12$ & $0.2-0.3 \times 0.5-1$ \\
\hline Gliding motility & - & + & - & $+\ddagger$ & - & - \\
\hline $\mathrm{NaCl}$ range $(\%, w / v)$ & $0-6$ & $0-5$ & $0-6$ & $0-6 \$$ & $0-5$ & $0-9$ \\
\hline Temperature range $\left({ }^{\circ} \mathrm{C}\right)$ & $6-37$ & $10-37$ & $18-37$ & $6-42 \$$ & $18-37$ & $10-37$ \\
\hline Hydrolysis of urea & + & + & + & - & + & - \\
\hline Nitrate reduction & -11 & -11 & -11 & -11 & - & - \\
\hline Nitrite reduction & + & $+{ }^{\infty}$ & + & + & + & - \\
\hline \multicolumn{7}{|l|}{ Enzyme activity (API ZYM): } \\
\hline Esterase (C4) & + & + & $\mathrm{W}$ & $\mathrm{W}$ & + & - \\
\hline Esterase lipase (C8) & + & + & $\mathrm{W}$ & $\mathrm{W}$ & + & - \\
\hline \multicolumn{7}{|l|}{ Oxidation of (GN2 MicroPlate): } \\
\hline Glycogen & - & - & - & - & + & + \\
\hline L-Arabinose & - & - & - & + & + & - \\
\hline$\alpha$-Ketoglutaric acid & - & - & $\mathrm{W}$ & + & + & + \\
\hline L-Alaninamide & - & - & + & - & + & - \\
\hline L-Glutamic acid & - & + & + & + & + & + \\
\hline Glycyl L-aspartic acid & - & + & + & + & + & + \\
\hline Glycyl L-glutamic acid & - & + & + & + & + & + \\
\hline L-Proline & - & + & + & + & + & + \\
\hline L-Serine & - & + & + & - & + & + \\
\hline L-Threonine & - & + & + & - & + & + \\
\hline Inosine & - & + & + & - & + & + \\
\hline L-Leucine & - & + & + & - & + & + \\
\hline L-Ornithine & - & - & + & - & + & + \\
\hline L-Alanine & - & + & + & - & + & + \\
\hline Succinamic acid & - & - & + & - & + & + \\
\hline DL-Lactic acid & - & + & + & - & + & + \\
\hline Methyl pyruvate & - & - & + & - & + & + \\
\hline Acetic acid & - & + & + & - & + & + \\
\hline DNA G $+C$ content $(\mathrm{mol} \%)$ & 34.3 & 34.29 & 33.89 & 33.99 & 36.79 & 35.89 \\
\hline
\end{tabular}

${ }^{\star}$ J. F. Bernardet, personal communication.

$\dagger$ Data from Cho et al. (2011); Zhang et al. (2008) and Vancanneyt et al. (1996), respectively.

\$Contradictory data were reported by Zhang et al. (2008) and Cho et al. (2011).

$\$$ Zhang et al. (2008) reported $\mathrm{NaCl}$ and temperature ranges for growth of $M$. profundi $\mathrm{D} 25^{\mathrm{T}}$ of $0-8 \%$ and $8-42{ }^{\circ} \mathrm{C}$, respectively.

IIMethod 1 of Tindall et al. (2007) and the corresponding API 20NE test both gave negative results, confirming the original reports by Cho et al. (2011), Zhang et al. (2008) and Vancanneyt et al. (1996).

SData from Cho et al. (2011). 
Chemotaxonomic characteristics were determined from cells grown at $28{ }^{\circ} \mathrm{C}$ for 2 days in trypticase soy broth (TSB; Difco). Fatty acid methyl esters of strain $\mathrm{MY} 5^{\mathrm{T}}$ and the three reference strains were prepared and analysed according to the standard protocol of the MIDI (Microbial Identification) system (Sasser, 1990) with Sherlock version 6.0 and the peaks were identified using the TSBA40 database. Strain $M Y 15^{\mathrm{T}}$ and the three reference strains contained $\mathrm{C}_{15: 0}$ iso and $\mathrm{C}_{17: 0}$ iso $3-\mathrm{OH}$ as the predominant fatty acids (Table 2). According to published data obtained using unspecified growth conditions, M. odoratus and M. pelagicus also contained the same dominant fatty acids (Yoon et al., 2006). Strain $M Y 15^{\mathrm{T}}$ differed from the reference strains by containing a significant amount of $\mathrm{C}_{15: 0}$ anteiso and only traces of summed feature 3 . The analysis of respiratory quinones was carried out by the Identification Service and Dr Brian Tindall, DSMZ, Braunschweig, Germany. In accordance with other members of the family Flavobacteriaceae, strain $\mathrm{MY}^{\mathrm{T}} 5^{\mathrm{T}}$ contained menaquinone 6 (MK-6) as the major respiratory quinone $(>99 \%)$. Strain MY $15^{\mathrm{T}}$ also contained $<1 \%$ of menaquinone 7 (MK-7), which was not reported in other species of the genus Myroides. The $\mathrm{G}+\mathrm{C}$ content of the DNA of strain $\mathrm{MY}^{\mathrm{T}}{ }^{\mathrm{T}}$ was $34.3 \mathrm{~mol} \%$

Table 2. Cellular fatty acid content (\%) of Myroides phaeus sp. nov. and other species of the genus Myroides

Strains: 1, Myroides phaeus sp. nov. MY15 ${ }^{\mathrm{T}} ; 2$, M. marinus $\mathrm{JS}-08^{\mathrm{T}}$; 3, M. odoratimimus LMG $4029^{\mathrm{T}}$; 4, M. profundi $\mathrm{D} 25^{\mathrm{T}}$; 5 , M. odoratus ATCC $4651^{\mathrm{T}}$ (Yoon et al., 2006; growth conditions unspecified); 6, $M$. pelagicus KCTC $12661^{\mathrm{T}}$ (Yoon et al., 2006; growth conditions unspecified). Data for 1-4 are from this study. -, Not detected; tr, trace $(<1 \%)$. Fatty acids amounting to $<1 \%$ of the total fatty acids in all strains listed are not shown.

\begin{tabular}{|lcccccc|}
\hline Fatty acid & $\mathbf{1}$ & $\mathbf{2}$ & $\mathbf{3}$ & $\mathbf{4}$ & $\mathbf{5}$ & $\mathbf{6}$ \\
\hline $\mathrm{C}_{14: 0}$ & $\operatorname{tr}$ & 1.2 & 1.4 & 1.0 & - & - \\
$\mathrm{C}_{16: 0}$ & 1.6 & 2.4 & 3.3 & 3.2 & - & - \\
$\mathrm{C}_{18: 0}$ & - & - & 2.0 & - & - & - \\
$\mathrm{C}_{13: 0}$ iso & 10.5 & 8.9 & 9.0 & 4.5 & $\operatorname{tr}$ & 7.4 \\
$\mathrm{C}_{15: 0}$ iso & 51.2 & 52.9 & 46.7 & 49.5 & 45.5 & 49.4 \\
$\mathrm{C}_{16: 0}$ iso & $\operatorname{tr}$ & 1.4 & 1.6 & $\operatorname{tr}$ & - & - \\
$\mathrm{C}_{15: 0}$ anteiso & 4.4 & $\operatorname{tr}$ & 1.6 & $\operatorname{tr}$ & 2.0 & 1.0 \\
$\mathrm{C}_{16: 0}$ 3-OH & 6.7 & 6.7 & 7.7 & 7.8 & 1.5 & 2.8 \\
$\mathrm{C}_{15: 0}$ iso 3-OH & 4.2 & 4.0 & 3.9 & 4.4 & 5.8 & 6.1 \\
$\mathrm{C}_{16: 0}$ iso 3-OH & $\operatorname{tr}$ & $\operatorname{tr}$ & 1.1 & $\operatorname{tr}$ & - & - \\
$\mathrm{C}_{17: 0}$ iso 3-OH & 12.9 & 9.8 & 10.1 & 12.5 & 21.2 & 10.1 \\
Summed features & & & & & & \\
3 & $\operatorname{tr}$ & 3.8 & 2.1 & 3.9 & $\operatorname{tr}$ & 1.9 \\
8 & - & - & 1.7 & - & - & - \\
9 & 2.6 & 5.3 & 3.3 & 8.6 & 13.8 & 13.1 \\
\hline
\end{tabular}

${ }^{*}$ Summed features are groups of two or three fatty acids that cannot be separated by GLC using the MIDI system. Summed feature 3 contained $\mathrm{C}_{16: 1} \omega 7 c$ and/or $\mathrm{C}_{15: 0}$ iso 2-OH; summed feature 8 contained $\mathrm{C}_{18: 1} \omega 6 c / \mathrm{C}_{18: 1} \omega 7 c$; summed feature 9 contained $\mathrm{C}_{17: 1} \omega 9 c$ iso and/or $\mathrm{C}_{16: 0}$ 10-methyl. as determined by the method of Mesbah \& Whitman (1989) using reverse-phase HPLC. This value falls within the range (33.8-36.7\%) reported for strains of the genus Myroides (Cho et al., 2011).

On the basis of phylogenetic inference and phenotypic characteristics, strain $\mathrm{MY}^{\mathrm{T}} 5^{\mathrm{T}}$ is assigned to the genus Myroides as a novel species for which the name Myroides phaeus sp. nov. is proposed. The additional data obtained in this study also make emended descriptions of the genus Myroides and the species M. profundi and M. marinus necessary.

\section{Emended description of the genus Myroides Vancanneyt et al. 1996}

Myroides (My.roi'des. Gr. n. myron perfume; Gr. adj. suffix oides similar to; N.L. masc. n. Myroides resembling perfume).

The following description includes characteristics taken from the original description as well as corrections and additions resulting from this study. Cells are strictly aerobic, Gram-staining-negative rods that may form chains of 4-10 cells in broth culture. Spores are not formed. Cells lack flagella and flagellar motility. Some species display gliding motility. A characteristic fruity odour is produced by most strains. Non-haemolytic on blood agar. All strains grow at $18-22{ }^{\circ} \mathrm{C}$ and at $37{ }^{\circ} \mathrm{C}$, and some strains grow at 6 and $42{ }^{\circ} \mathrm{C}$. Oxidase- and catalase-positive. Most species reduce nitrite, but do not reduce nitrate. Some strains produce flexirubin-type and diffusible pigments on LB agar. Menaquinone 6 is the major isoprenoid quinone. The dominant fatty acids are $\mathrm{C}_{15: 0}$ iso and $\mathrm{C}_{17: 0}$ iso $3-\mathrm{OH}$. The DNA G $+\mathrm{C}$ content ranges from 33 to $37 \mathrm{~mol} \%$. The type species is $M$. odoratus.

\section{Emended description of Myroides profundi Zhang et al. 2009}

The description is the same as that given by Zhang et al. (2008) except that gliding motility is present and that the $\mathrm{NaCl}$ and temperature ranges for growth are $0-6 \%(\mathrm{w} / \mathrm{v})$ and $6-42{ }^{\circ} \mathrm{C}$, respectively.

\section{Emended description of Myroides marinus Cho et al. 2011}

The description is the same as that given by Cho et al. (2011) except that nitrite is reduced.

\section{Description of Myroides phaeus sp. nov.}

Myroides phaeus (pha'e.us. Gr. adj. phaios brown; N.L. masc. adj. phaeus brown, referring to the colour of the colonies).

Displays the following characteristics in addition to those listed in the genus description. Cells are straight rods that occur singly or in pairs and are $0.4-0.5 \mu \mathrm{m}$ in diameter and 
$0.7-1.2 \mu \mathrm{m}$ in length. Gliding motility is not observed. Colonies grown on LB agar are circular with regular margins, convex and yellow to brown. The pigments are diffusible and non-flexirubin type. Growth occurs at 6$37{ }^{\circ} \mathrm{C}$ (optimum, $28{ }^{\circ} \mathrm{C}$; no growth occurs at 4 or $42{ }^{\circ} \mathrm{C}$ ) and at $\mathrm{pH} 5.0-10.0$ (optimum, $\mathrm{pH}$ 8). $\mathrm{NaCl}$ is not required for growth. Tolerates up to $6.0 \% \mathrm{NaCl}(\mathrm{w} / \mathrm{v})$ (optimum, $1.0 \%)$. Gelatin and DNA are hydrolysed, while casein, Tween 80, agar, starch, CM-cellulose and egg yolk are not. Positive in tests for arginine dihydrolase and urease activities, citrate utilization and nitrite reduction and for the Voges-Proskauer reaction. Negative result in tests for $\beta$-galactosidase (ONPG), lysine decarboxylase, ornithine decarboxylase, tryptophan deaminase and $\beta$-glucosidase activities, production of hydrogen sulfide and indole, and reduction of nitrate. In the API ZYM gallery, alkaline phosphatase, esterase (C4), esterase lipase (C8), lipase (C14), cystine arylamidase, acid phosphatase and naphthol-AS-BI-phosphohydrolase activities are present, but leucine arylamidase, valine arylamidase, trypsin, $\alpha$ chymotrypsin, $\alpha$-galactosidase, $\beta$-galactosidase, $\beta$-glucuronidase, $\alpha$-glucosidase, $\beta$-glucosidase, $N$-acetyl- $\beta$-glucosaminidase, $\alpha$-mannosidase and $\alpha$-fucosidase activities are absent. Acid is produced from inositol, D-sorbitol, sucrose and amygdalin, but not from D-glucose, D-mannitol, L-rhamnose, melibiose or L-arabinose. In the GN2 MicroPlate, Tween 80, monomethyl succinate, succinic acid, L-asparagine and L-aspartic acid are oxidized; all other substrates in the GN2 MicroPlate are not oxidized. The main cellular fatty acids ( $>10 \%$ of the total fatty acids) are $\mathrm{C}_{15: 0}$ iso, $\mathrm{C}_{17: 0}$ iso $3-\mathrm{OH}$ and $\mathrm{C}_{13: 0}$ iso.

The type strain, MY15 ${ }^{\mathrm{T}}\left(=\right.$ DSM $\left.23313^{\mathrm{T}}=\mathrm{LMG} 25566^{\mathrm{T}}\right)$, was isolated from human saliva in China. The DNA G + C content of the type strain is $34.3 \mathrm{~mol} \%$.

\section{Acknowledgements}

This work was supported by the National High Technology R\&D Program of China (no. 2007AA09Z434) and the National Natural Science Foundation of China (no. 40876067). Professor Seung Bum Kim (Chungnam National University, Korea) and Professor Yuzhong Zhang (Shandong University, China) kindly provided Myroides marinus $\mathrm{JS}-08^{\mathrm{T}}$ and Myroides profundi $\mathrm{D} 25^{\mathrm{T}}$, respectively.

\section{References}

Bernardet, J.-F., Nakagawa, Y. \& Holmes, B. (2002). Proposed minimal standards for describing new taxa of the family Flavobacteriaceae and emended description of the family. Int J Syst Evol Microbiol 52, 1049-1070.

Beveridge, T. J., Lawrence, J. R. \& Murray, R. G. E. (2007). Sampling and staining for light microscopy. In Methods for General and Molecular Microbiology, pp. 19-33. Edited by C. A. Reddy, T. J. Beveridge, J. A. Breznak, G. Marzluf, T. M. Schmidt \& L. R. Snyder. Washington, DC: American Society for Microbiology.

Breznak, J. A. \& Costilow, R. N. (1994). Physicochemical factors in growth. In Methods for General and Molecular Bacteriology, pp.
137-154. Edited by P. Gerhardt, R. G. E. Murray, W. A. Wood \& N. R. Krieg. Washington, DC: American Society for Microbiology.

Cho, S.-H., Chae, S.-H., Im, W.-T. \& Kim, S. B. (2011). Myroides marinus sp. nov., a member of the family Flavobacteriaceae, isolated from seawater. Int J Syst Evol Microbiol 61, 938-941.

Chun, J., Lee, J.-H., Jung, Y., Kim, M., Kim, S., Kim, B. K. \& Lim, Y. W. (2007). EzTaxon: a web-based tool for the identification of prokaryotes based on $16 \mathrm{~S}$ ribosomal RNA gene sequences. Int J Syst Evol Microbiol 57, 2259-2261.

Davis, J. M., Peel, M. M. \& Gillians, J. A. (1979). Colonization of an amputation site by Flavobacterium odoratum after gentamicin therapy. Med J Aust 2, 703-704.

Ferrer, C., Jakob, E., Pastorino, G. \& Juncos, L. I. (1995). Right-sided bacterial endocarditis due to Flavobacterium odoratum in a patient on chronic hemodialysis. Am J Nephrol 15, 82-84.

Green, B. T., Green, K. \& Nolan, P. E. (2001). Myroides odoratus cellulitis and bacteremia: case report and review. Scand J Infect Dis 33, 932-934.

Holmes, B., Snell, J. J. S. \& Lapage, S. P. (1977). Revised description, from clinical isolates, of Flavobacterium odoratum Stutzer and Kwaschnina 1929, and designation of the neotype strain. Int J Syst Bacteriol 27, 330-336.

Hsueh, P. R., Wu, J. J., Hsiue, T. R. \& Hsieh, W. C. (1995). Bacteremic necrotizing fasciitis due to Flavobacterium odoratum. Clin Infect Dis 21, 1337-1338.

Hu, Z.-Y. \& Li, Y. (2007). Pseudidiomarina sediminum sp. nov., a marine bacterium isolated from coastal sediments of Luoyuan Bay in China. Int J Syst Evol Microbiol 57, 2572-2577.

Hugo, C. J., Bruun, B. \& Jooste, P. J. (2006). The genera Empedobacter and Myroides. In The Prokaryotes, 3rd edn, vol. 7, pp. 630-637. Edited by M. Dworkin, S. Falkow, E. Rosenberg, K. H. Schleifer \& E. Stackebrandt. New York: Springer.

Jin, G., Wang, S., Yu, M., Yan, S. \& Zhang, X.-H. (2010). Identification of a marine antagonistic strain JG1 and establishment of a polymerase chain reaction. Aquacult Res 41, 1867-1874.

Macfarlane, D. E., Baum-Thureen, P. \& Crandon, I. (1985). Flavobacterium odoratum ventriculitis treated with intraventricular cefotaxime. J Infect 11, 233-238.

Mesbah, M. \& Whitman, W. B. (1989). Measurement of deoxyguanosine/thymidine ratios in complex mixtures by highperformance liquid chromatography for determination of the mole percentage guanine + cytosine of DNA. J Chromatogr A 479, 297306.

Sasser, M. (1990). Identification of bacteria by gas chromatography of cellular fatty acids, Technical Note 101. Newark, DE: MIDI Inc.

Tamura, K., Dudley, J., Nei, M. \& Kumar, S. (2007). MEGA4: molecular evolutionary genetics analysis (MEGA) software version 4.0. Mol Biol Evol 24, 1596-1599.

Thompson, J. D., Gibson, T. J., Plewniak, F., Jeanmougin, F. \& Higgins, D. G. (1997). The CLUSTAL_X windows interface: flexible strategies for multiple sequence alignment aided by quality analysis tools. Nucleic Acids Res 25, 4876-4882.

Tindall, B. J., Sikorski, J., Smibert, R. M. \& Krieg, N. R. (2007). Phenotypic characterization and the principles of comparative systematics. In Methods for General and Molecular Microbiology, pp. 330-393. Edited by C. A. Reddy, T. J. Beveridge, J. A. Breznak, G. Marzluf, T. M. Schmidt \& L. R. Snyder. Washington, DC: American Society for Microbiology.

Vancanneyt, M., Segers, P., Torck, U., Hoste, B., Bernardet, J.-F., Vandamme, P. \& Kersters, K. (1996). Reclassification of Flavobacterium odoratum (Stutzer 1929) strains to a new genus, 
Myroides, as Myroides odoratus comb. nov. and Myroides odoratimimus sp. nov. Int J Syst Bacteriol 46, 926-932.

Yağcı, A., Cerikçioğlu, N., Kaufmann, M. E., Malnick, H., Söyletir, G., Babacan, F. \& Pitt, T. L. (2000). Molecular typing of Myroides odoratimimus (Flavobacterium odoratum) urinary tract infections in a Turkish hospital. Eur J Clin Microbiol Infect Dis 19, 731-732.
Yoon, J., Maneerat, S., Kawai, F. \& Yokota, A. (2006). Myroides pelagicus sp. nov., isolated from seawater in Thailand. Int J Syst Evol Microbiol 56, 1917-1920.

Zhang, X.-Y., Zhang, Y.-J., Chen, X.-L., Qin, Q.-L., Zhao, D.-L., Li, T.-G., Dang, H.-Y. \& Zhang, Y.-Z. (2008). Myroides profundi sp. nov., isolated from deep-sea sediment of the southern Okinawa Trough. FEMS Microbiol Lett 287, 108-112. 